\title{
Nonlinear Control of Back-to-Back VSC-HVDC System via Command-Filter Backstepping
}

\author{
Jie Huang, ${ }^{1}$ Dezhi Xu, ${ }^{1}$ Wenxu Yan, ${ }^{1}$ Le Ge, ${ }^{2}$ and Xiaodong Yuan ${ }^{3}$ \\ ${ }^{1}$ Institute of Electrical Engineering and Intelligent Equipment, School of Internet of Things Engineering, \\ Jiangnan University, Wuxi 214122, China \\ ${ }^{2}$ School of Electric Power Engineering, Nanjing Institute of Technology, Nanjing 211167, China \\ ${ }^{3}$ Center of Power Grid Technology, State Grid Jiangsu Electric Power Company Research Institute, Nanjing 211103, China
}

Correspondence should be addressed to Dezhi Xu; xudezhi@jiangnan.edu.cn

Received 30 October 2016; Revised 7 January 2017; Accepted 9 February 2017; Published 26 February 2017

Academic Editor: Jose F. Silva

Copyright (C) 2017 Jie Huang et al. This is an open access article distributed under the Creative Commons Attribution License, which permits unrestricted use, distribution, and reproduction in any medium, provided the original work is properly cited.

\begin{abstract}
This paper proposed a command-filtered backstepping controller to improve the dynamic performance of back-to-back voltagesource-converter high voltage direct current (BTB VSC-HVDC). First, the principle and model of BTB VSC-HVDC in $a b c$ and $d-q$ frame are described. Then, backstepping method is applied to design a controller to maintain the voltage balance and realize coordinated control of active and reactive power. Meanwhile, command filter is introduced to deal with the problem of input saturation and explosion of complexity in conventional backstepping, and a filter compensation signal is designed to diminish the adverse effects caused by the command filter. Next, the stability and convergence of the whole system are proved via the Lyapunov theorem of asymptotic stability. Finally, simulation results are given to demonstrate that proposed controller has a better dynamic performance and stronger robustness compared to the traditional PID algorithm, which also proves the effectiveness and possibility of the designed controller.
\end{abstract}

\section{Introduction}

With the rapid development of economy, the demand for energy is rising [1]. There is a great technological development in the power generation, transmission, distribution, and other aspects [2]. However, with the development of power energy, there are a lot of new technical problems in terms of transmission, such as economic grid-connected technology of decentralized and small renewable energy power generation, power supply technology of isolated island and other passive load, expansion of urban electric load capacity and reconstruction technology of urban power grid, remote power supply, and grid connection of nonsynchronous power grid and microgrid. The traditional AC and DC transmission technology is still unable to effectively solve the above problems in the technical and economic benefits [2]. With the development of power electronics and control technology, the above problems can be solved by using voltage-source-converter high voltage direct current
(VSC-HVDC) composed of IGBT, IGCT, and other new full controlled power electronic devices, which can realize the independent control of active power and reactive power [3]. VSC-HVDC has the following two main advantages, one is that VSC-HVDC transmission technology supplies power to the passive load without the commutation voltage of the AC system, the other one is that VSC-HVDC does not need AC power grid to provide reactive power to stabilize DC voltage, which can work as static synchronous compensator (STATCOM) [2-4]. Moreover, the other advantages are the following: large transmission capacity, small harmonic of output voltage, low cost and little loss, and the current of the AC-side being controlled so that the short-circuit capacity of the system can not be added [2-5]. Therefore, VSC-HVDC play a very significant role in the gird-connection of largescale wind farm and the development of new technologies such as urban power supply and isolated island power supply, which meet the energy demand of continued rapid growth and efficient use of energy. 
Nowadays, the back-to-back VSC-HVDC (BTB VSCHVDC) is playing a significant part from the start of HVDC, which gets extensive attention in the field of interconnection of synchronous and asynchronous AC system, wind power networking, and so forth [6]. Power flow control range of BTB VSC-HVDC is greater than unified power flow controller (UPFC); meanwhile UPFC is a series structure, so it will withstand large short-circuit current for series part when the feeder is fault, while the BTB VSC-HVDC is parallel structure, which has the higher security. So BTB VSC-HVDC technology has become a hot research topic in the field of transmission [7-10].

Recently, there are many relevant researches about BTB VSC-HVDC [7-12]. In [7], a DC side capacitor voltage balance control based on space vector modulation (SVM) is proposed, which is used for five-level BTB VSC-HVDC to control and maintain the voltage balance of the DC side capacitors. In [8], a phase-disposition sine-wave pulse-width modulation (SPWM) strategy including voltage balancing strategy is applied for modular multilevel BTB VSC-HVDC, which focuses on the dynamic performance of system under both balanced and unbalanced operation condition. Reference [9] proposed a model predictive control for BTB VSCHVDC to eliminate the circulating currents of converter arm, control real and reactive power, and maintain the voltage balance of DC-link. These methods improve the control performance and have good stability and fast dynamic response. However, their control scheme has added complexity and cost to the system, which contributes to the fact that the design scheme of the controller and the determination of the parameters are more difficult.

In recent years, the backstepping method, as a design tool for nonlinear control [13], has received great attention from scholars, which has become an effective method for nonlinear control design. The method is designed on the basis of nonlinear system, which can retain some useful nonlinear terms. The basic idea of backstepping is to decompose the complex nonlinear system into several subsystems; then Lyapunov function and virtual control are designed in each subsystem. Finally, they go "back to" the entire system until the completion of the entire control law $[13,14]$. The whole design process and the adjustment of parameter in backstepping controller are convenient, which is easy to be accepted by the engineering staff. Backstepping is widely used in the control system design of VSC-HVDC, which has obtained some achievements [15-22]. But this kind of controller has the following two main disadvantages: (1) the derivative of each virtual controller needs to be analyzed and calculated, and the calculation process is very complicated, so it is difficult to be applied in practical engineering; (2) physical limitations in practical systems are not considered in the design process of controller, which may cause the problem of control saturation [14]. Currently, there are many ways to solve the above problems, such as dynamic surface control $[23,24]$ and command filter $[25,26]$. Among them, command filter is a more effective method compared to the dynamic surface control, because the constraint of amplitude, rate, and bandwidth are introduced in the filter process of command filter, which is more convenient to modulate and limit the virtual control signal and the actual control signal to meet the actual control requirements. By adding constraints on input control signals, the control effect and stability of the controller can be effectively guaranteed, which increases the feasibility of the controller in engineering application. Moreover, filter compensation is introduced in the control, which can realize the asymptotic tracking of reference signal rather than bounded tracking in dynamic surface control.

The rest of paper is organized as follows. In Section 2, the model of BTB VSC-HVDC in $a b c$ and $d-q$ frame are described. In Section 3, command-filtered backstepping control is designed for BTB VSC-HVDC and the stability of system is proved by Lyapunov stability theory. In Section 4, simulation results are shown to demonstrate the effectiveness of the designed controller. Finally, some conclusions are discussed in Section 5.

\section{Model of Back-to-Back VSC-HVDC}

Mathematical modeling is the basis of the research on control strategy, so in this section, the mathematical models of main circuit of BTB VSC-HVDC in $a b c$ and $d-q$ reference frame are described, which lays the foundation for the research of coordinated control of active and reactive power and the voltage balance of BTB VSC-HVDC.

2.1. Model of Back-to-Back VSC-HVDC in abc Frame. The equivalent system model for BTB VSC-HVDC is shown in Figure 1 [7], which is composed of two VSC converter stations, DC side capacitor $C$ and reactor $\left(L_{1}\right.$ and $\left.L_{2}\right)$. Among them, the DC capacitor provides voltage support for the VSC and reduces the DC side harmonics, the reactor is used to filter out the harmonic of output current, and the loss of the converter and line is represented by equivalent resistances $R_{1}$ and $R_{2}$.

The dynamic mathematical model of AC-side voltage in the $a b c$ frame can be expressed as follows [15]:

$$
\mathbf{L}_{k} \frac{d \mathbf{i}_{k}^{a, b, c}}{d t}=-\mathbf{R}_{k} \mathbf{i}_{k}^{a, b, c}+\mathbf{u}_{s k}^{a, b, c}-\mathbf{u}_{r k}^{a, b, c},
$$

where $k=1$ as $\mathrm{AC}_{1}$ and $\mathrm{VSC}_{1}$ system, $k=2$ as $\mathrm{AC}_{2}$ and $\mathrm{VSC}_{2}$ system, $\mathbf{u}_{s k}^{a, b, c}$ is the vector of the grid-side phase voltages $\left(u_{s k}^{a}, u_{s k}^{b}, u_{s k}^{c}\right), \mathbf{i}_{k}^{a, b, c}$ is the vector of the grid-side currents voltages $\left(i_{s k}^{a}, i_{s k}^{b}, i_{s k}^{c}\right), \mathbf{L}_{k}$ is the vector of equivalent inductance, $\mathbf{R}_{k}$ is the vector of equivalent resistance, and $\mathbf{u}_{r k}^{a, b, c}$ is the vector of phase voltages in the AC-side of the VSC. Meanwhile, the active power $P_{k}$ and reactive power $Q_{k}$ can be expressed as follows [15]:

$$
\begin{aligned}
P_{k} & =u_{s k}^{a} i_{k}^{a}+u_{s k}^{b} i_{k}^{b}+u_{s k}^{c} i_{k}^{c} \\
Q_{k} & =\frac{1}{\sqrt{3}}\left(u_{a b} i_{c}+u_{b c} i_{a}+u_{c a} i_{b}\right),
\end{aligned}
$$

where $u_{a b}, u_{b c}, u_{c a}$ are the grid-side line voltages and $i_{a}, i_{b}, i_{c}$ are the grid-side line currents. 


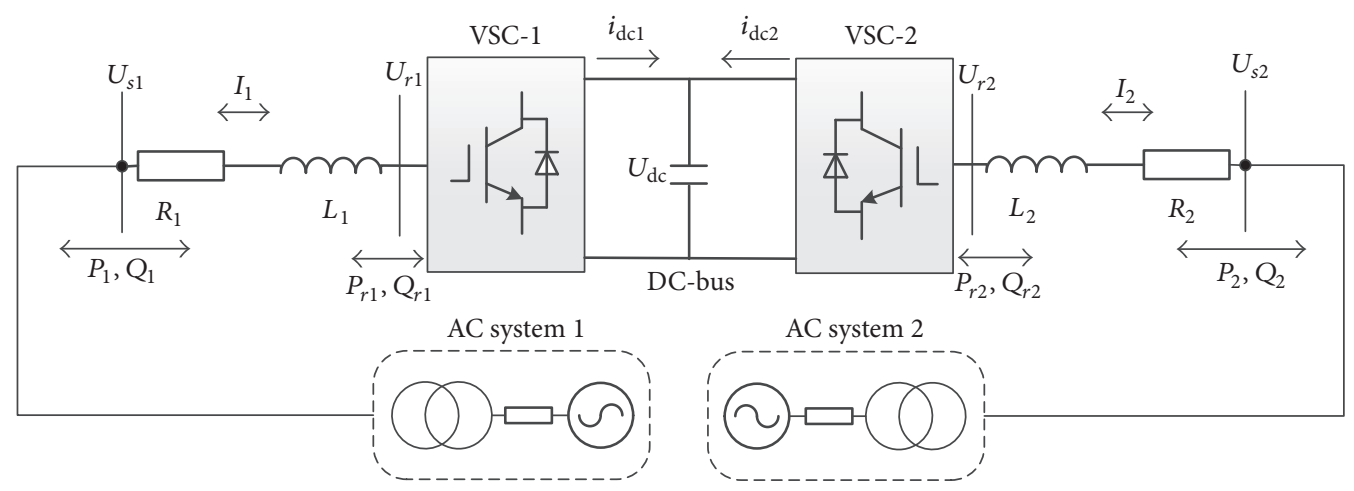

FIGURE 1: Equivalent physical model for BTB VSC-HVDC system.

The dynamic changes of DC-bus voltage can be drawn from Figure 1 as follows:

$$
C \frac{d u_{\mathrm{dc}}}{d t}=i_{\mathrm{dc} 1}+i_{\mathrm{dc} 2}-\frac{u_{\mathrm{dc}}}{R_{p}}
$$

where $R_{p}$ is the total estimation of switching losses of VSC.

2.2. Model of Back-to-Back VSC-HVDC in d-q Frame. VSC$\mathrm{HVDC}$ is transformed to $d-q$ synchronous rotating reference frame as follows [16]:

VSC-1 converter stations:

$$
\begin{aligned}
& L_{1} \frac{d i_{d 1}}{d t}=\omega_{1} L_{1} i_{q 1}-R_{1} i_{d 1}+u_{r d 1}-u_{s d 1} \\
& L_{1} \frac{d i_{q 1}}{d t}=-\omega_{1} L_{1} i_{d 1}-R_{1} i_{q 1}+u_{r q 1}-u_{s q 1},
\end{aligned}
$$

VSC-2 converter stations:

$$
\begin{aligned}
& L_{2} \frac{d i_{d 2}}{d t}=\omega_{2} L_{2} i_{q 2}-R_{2} i_{d 2}+u_{s d 2}-u_{r d 2} \\
& L_{2} \frac{d i_{q 2}}{d t}=-\omega_{2} L_{2} i_{d 2}-R_{2} i_{q 2}+u_{s q 2}-u_{r q 2},
\end{aligned}
$$

where $\omega_{1}, \omega_{2}$ are the angular frequencies of two sides' AC system, respectively, $i_{d k}, i_{q k}$ are the $d$-axis and $q$-axis currents of the power grid, respectively, $u_{s d k}$ and $u_{s q k}$ are the $d$-axis and $q$-axis grid-side voltages, respectively, and $u_{r d k}$ and $u_{r q k}$ are the $d$-axis and $q$-axis voltages in the AC-side of the VSC.

When the losses in the converters are ignored, the active power balance equation can be described as follows [17]:

$$
P_{\mathrm{dc}}=P_{r 1}+P_{r 2}
$$

where $P_{r 1}, P_{r 2}$ are the active power supplied by VSC-1 and VSC-2, respectively, and $P_{r 1}, P_{r 2}$ can be given as

$$
\begin{aligned}
& P_{r 1}=\frac{3}{2}\left(u_{r d 1} i_{d 1}+u_{r q 1} i_{q 1}\right) \\
& P_{r 2}=\frac{3}{2}\left(u_{r d 2} i_{d 2}+u_{r q 2} i_{q 2}\right) .
\end{aligned}
$$

Generally, the losses in the transformer are very small, so (7) can be approximated as follows [17]:

$$
\begin{aligned}
& P_{r 1} \approx P_{1}=\frac{3}{2}\left(u_{s d 1} i_{d 1}+u_{s q 1} i_{q 1}\right) \\
& P_{r 2} \approx P_{2}=\frac{3}{2}\left(u_{s d 2} i_{d 2}+u_{s q 2} i_{q 2}\right) .
\end{aligned}
$$

Then, the $d$-axis is located in the direction of the voltage vector of the AC system by phase-locked loops (PLL); therefore $u_{s q 1}, u_{s q 2}$ are equal to 0 , while $u_{s d 1}, u_{s d 2}$ are equal to the magnitude of $u_{s k}$; therefore, (8) can be calculated as follows:

$$
\begin{aligned}
& P_{1}=\frac{3}{2} u_{s d 1} i_{d 1} \\
& P_{2}=\frac{3}{2} u_{s d 2} i_{d 2} .
\end{aligned}
$$

Similarly, reactive power can be calculated as follows:

$$
\begin{aligned}
& Q_{1}=-\frac{3}{2} u_{s d 1} i_{q 1} \\
& Q_{2}=-\frac{3}{2} u_{s d 2} i_{q 2} .
\end{aligned}
$$

In the synthesis, according to (6), (8)-(10), the power balance equation for the DC-bus voltage can be derived as follows:

$$
C u_{\mathrm{dc}} \frac{d u_{\mathrm{dc}}}{d t}=\frac{3}{2}\left(u_{s d 1} i_{d 1}+u_{s d 2} i_{d 2}\right)
$$

Remark 1 . In steady state, $u_{s d 1}$ and $u_{s d 2}$ are constant, so the active and reactive power exchanging between $\mathrm{VSC}_{1}$ and $\mathrm{AC}_{1}$ can be adjusted by controlling the currents $i_{d 1}$ and $i_{q 1}$. Similarly, the active and reactive power exchanging between $\mathrm{VSC}_{2}$ and $\mathrm{AC}_{2}$ can be adjusted by controlling the currents $i_{d 2}$ and $i_{q 2}$.

Remark 2. In order to ensure the safe operation of system, it is necessary to maintain the DC side capacitor voltage near its rated value in the process of operation. And we can see from (13) the operation constraint that the exchange of active power between the two sides AC system and back-to-back converter must be kept balanced. 


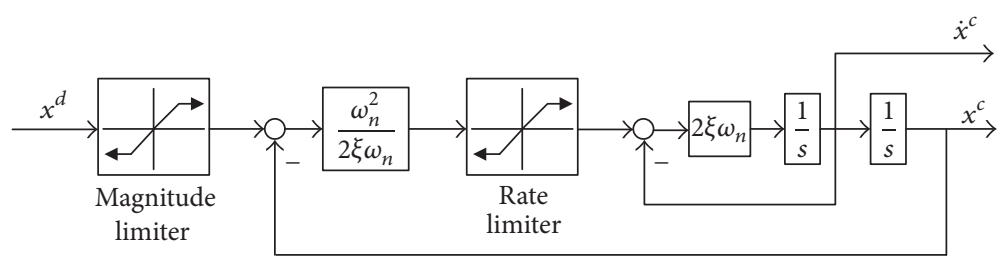

FIGURE 2: Structure of constrained command filter.

So the control problem of power exchanging between BTB VSC-HVDC and two sides AC system can be converted to power tracking problem under the constraint condition of the constant voltage balance of DC capacitor voltage.

\section{Design of Command-Filtered Backstepping Controller}

In this section, command-filtered backstepping controller is designed for BTB VSC-HVDC. First, backstepping control technique is applied to the overall controller design of the system. Then, the command filter is used to overcome complex problems of derivation of virtual control signal in the design of conventional backstepping control law, which avoids the unacceptable defects of differential operation in engineering applications. Moreover, constrained command filter can also handle problem of input saturation in backstepping controller. However, command filter will generate filter error which can affect the performance of the controller, so filter compensation signal is designed to eliminate this effect.

The BTB VSC-HVDC usually adopts constant DC voltage control and reactive power control in the one-side converter, and active and reactive power control are adopted in the other side of the converter. The outer loop control is used to determine the current reference, and the inner loop control is used to realize the fast tracking of the current reference.

The design procedure of the controller for BTB VSCHVDC is deduced as follows. First, the controller of VSC-1 controlling the $\mathrm{DC}$ voltage and reactive power is derived step by step as follows.

Step 1. For the VSC-1, the tracking errors are defined as

$$
\begin{aligned}
& e_{1}=u_{\mathrm{dc}}-u_{\mathrm{dc}}^{c} \\
& e_{2}=i_{d 1}-i_{d 1}^{c} \\
& e_{3}=i_{q 1}-i_{q 1}^{c},
\end{aligned}
$$

where $u_{\mathrm{dc}}^{c}$ is the reference voltage of DC side, $i_{q 1}^{c}$ is the reference current in $q$-axis which can be obtained from (11), and $i_{d 1}^{c}$ is the filtered command from virtual controller $i_{d 1}^{d}$.

From (4), (13), and (14), the differential of the tracking errors can be computed as

$$
\dot{e}_{1}=\frac{3}{2 C u_{\mathrm{dc}}}\left(u_{s d 1} i_{d 1}+u_{s d 2} i_{d 2}\right)-\dot{u}_{\mathrm{dc}}^{c}
$$

$$
\begin{aligned}
& \dot{e}_{2}=\omega_{1} L_{1} i_{q 1}-R_{1} i_{d 1}+u_{r d 1}-u_{s d 1}-\dot{i}_{d 1}^{c} \\
& \dot{e}_{3}=-\omega_{1} L_{1} i_{d 1}-R_{1} i_{q 1}+u_{r q 1}-u_{s q 1}-\dot{i}_{q 1}^{c} .
\end{aligned}
$$

Step 2. The candidate Lyapunov function is chosen to stabilize (15) as follows:

$$
V_{1}=\frac{1}{2} e_{1}^{2}
$$

And the time derivative of Lyapunov function $V_{1}$ is derived as

$$
\begin{aligned}
\dot{V}_{1}= & e_{1} \dot{e}_{1} \\
= & -k_{1} e_{1}^{2} \\
& +e_{1}\left[\frac{3}{2 C u_{\mathrm{dc}}}\left(u_{s d 1} i_{d 1}+u_{s d 2} i_{d 2}\right)-\dot{u}_{\mathrm{dc}}^{c}+k_{1} e_{1}\right] .
\end{aligned}
$$

So the virtual controller $i_{d 1}^{d}$ can be chosen as

$$
i_{d 1}^{d}=\frac{2 C u_{\mathrm{dc}}}{3 u_{s d 1}}\left(\dot{u}_{\mathrm{dc}}^{c}-k_{1} e_{1}\right)-\frac{u_{s d 2} i_{d 2}}{u_{s d 1}}
$$

where $k_{1}$ is a designed positive constant. Substituting (20) into (19), we can obtain that $\dot{V}_{1}<0$. Therefore, the subsystem is asymptotically stable according to Lyapunov stability theory.

Step 3. A command filter is applied to solve the effect of differential expansion of time derivative of (20) and input saturation of the controller, which is shown in Figure 2. Passing $i_{d 1}^{d}$ through the command filter, we can obtain the filtered command $i_{d 1}^{c}$ and its derivative $\dot{i}_{d 1}^{c}$. Moreover, the state space expression of constrained command filter is represented as

$$
\left[\begin{array}{c}
\dot{q}_{1} \\
\dot{q}_{2}
\end{array}\right]=\left[2 \xi \omega_{n}\left[S_{R}\left(\frac{\omega_{n}^{2}}{2 \xi \omega_{n}}\left(S_{M}(u)-q_{1}\right)\right)-q_{2}\right]\right],
$$

where $q_{1}=x_{d}^{c}, q_{2}=\dot{x}_{d}^{c}, u=x_{d}, \xi$ is the damping of the command filter, $\omega_{n}$ is the bandwidth, and $S_{R}(\cdot)$ and $S_{M}(\cdot)$ represent the rate and magnitude limit, respectively.

Remark 3. According to (21), if the input $x_{d}$ is bounded, $x_{d}^{c}$ and $\dot{x}_{d}^{c}$ are bounded and continuous. The error $x_{c}-x_{d}$ can be adjusted by bandwidth $\omega_{n}$. With the increase of the 


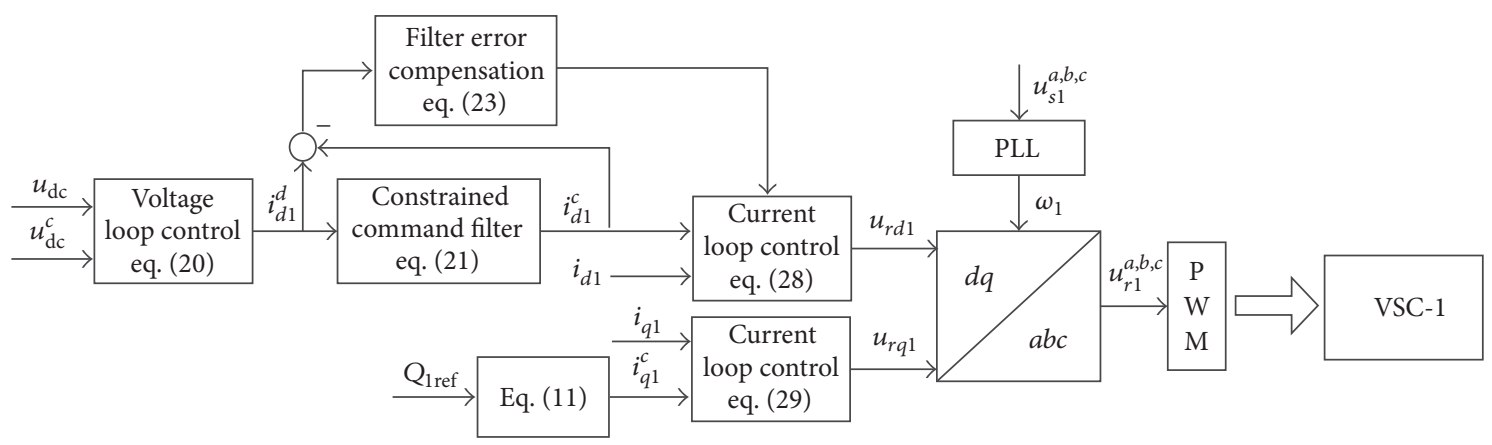

FIGURE 3: Block diagram of command-filtered backstepping designed for VSC-1.

bandwidth $\omega_{n}$, the signal $x_{d}^{c}$ implemented by the controller can be faster and more accurate to converge to $x_{d}$. And the first-order differential signal is obtained by the integral method, which can effectively overcome the effect of the amplified noise signal caused by the differential operation to the desired signal.

However, there is a filtering error generated by command filter, which will increase the difficulty to get minor tracking error and degrade the dynamic response of system. So the influence of filter error is considered in the controller design and the tracking error needs to be redefined as

$$
\bar{e}_{1}=e_{1}-\psi
$$

And the filter compensation signal is designed as

$$
\dot{\psi}=-k_{1} \dot{\psi}+\frac{3 u_{s d 1}}{C u_{\mathrm{dc}}}\left(i_{d 1}^{c}-i_{d 1}^{d}\right) .
$$

Step 4. In order to stabilize (16) and (17), Lyapunov function $V_{2}$ is designed as

$$
V_{2}=\frac{1}{2}\left(\bar{e}_{1}^{2}+e_{2}^{2}+e_{3}^{2}\right)
$$

The time derivative of Lyapunov function $V_{2}$ can be computed as

$$
\dot{V}_{2}=\bar{e}_{1} \dot{\bar{e}}_{1}+e_{2} \dot{e}_{2}+e_{3} \dot{e}_{3} \text {. }
$$

According to (13), (20), and (23), the time derivative of $\bar{e}_{1}$ can be calculated as

$$
\begin{aligned}
\dot{\bar{e}}_{1}= & \frac{3}{2 C u_{\mathrm{dc}}}\left(u_{s d 1} i_{d 1}+u_{s d 2} i_{d 2}\right)-\dot{u}_{\mathrm{dc}}^{c}+k_{1} \psi \\
& -\frac{3 u_{s d 1}}{2 C u_{\mathrm{dc}}}\left[i_{d 1}^{c}-\frac{2 C u_{\mathrm{dc}}\left(\dot{u}_{\mathrm{dc}}^{c}-k_{1} e_{1}\right)-3 u_{s d 2} i_{d 2}}{3 u_{s d 1}}\right] \\
= & \frac{3 u_{s d 1}}{2 C u_{\mathrm{dc}}} e_{2}-k_{1} \bar{e}_{1} .
\end{aligned}
$$

Substituting (16), (17), and (26) into (25), $\dot{V}_{2}$ can be calculated as

$$
\begin{aligned}
\dot{V}_{2} & =-k_{1} \bar{e}_{1}^{2}-k_{2} e_{2}^{2}-k_{3} e_{3}^{2}+e_{2}\left(\frac{3 u_{s d 1}}{2 C u_{\mathrm{dc}}} \bar{e}_{1}+\omega_{1} i_{q 1}\right. \\
& \left.-\frac{R_{1}}{L_{1}} i_{d 1}+\frac{u_{r d 1}-u_{s d 1}}{L_{1}}-\dot{i}_{d 1}^{c}+k_{2} e_{2}\right)+e_{3}\left(-\omega_{1} i_{d 1}\right. \\
& \left.-\frac{R_{1}}{L_{1}} i_{q 1}+\frac{u_{r q 1}-u_{s q 1}}{L_{1}}-\dot{i}_{q 1}^{c}+k_{3} e_{3}\right)
\end{aligned}
$$

where $k_{2}$ and $k_{3}$ are the designed positive constant. Finally, we choose two control inputs for VSC-1 as

$$
\begin{gathered}
u_{r d 1}=L_{1}\left(-\frac{3 u_{s d 1}}{2 C u_{\mathrm{dc}}} \bar{e}_{1}-\omega_{1} i_{q 1}+\frac{R_{1}}{L_{1}} i_{d 1}+\frac{u_{s d 1}}{L_{1}}+\dot{i}_{d 1}^{c}\right. \\
\left.-k_{2} e_{2}\right) \\
u_{r q 1}=L_{1}\left(-\omega_{1} i_{d 1}+\frac{R_{1}}{L_{1}} i_{q 1}+\frac{u_{s q 1}}{L_{1}}+\dot{i}_{q 1}^{c}-k_{3} e_{3}\right) .
\end{gathered}
$$

Then, we can obtain

$$
\dot{V}_{2}=-k_{1} \bar{e}_{1}^{2}-k_{2} e_{2}^{2}-k_{3} e_{3}^{2}<0 \text {. }
$$

Thus, it is proven that the subsystem for VSC-1 is asymptotically stable by Lyapunov stability theory. In order to clarify the design of subsystem, the block diagram of the designed controller for VSC-1 is displayed in Figure 3.

Remark 4. Since the command filter is applied in the backstepping controller to avoid the derivation signal $i_{d 1}^{d}$ of the virtual control by use of the integrated signal $i_{d 1}^{c}$, the designed controller in this paper is more concise than the traditional backstepping controller [18], which simplifies the program and reduces the amount of calculation of the controller. Therefore, command-filtered backstepping is more suitable for engineering applications.

Then, the controller that controls the active and reactive power for VSC-2 is derived as follows. 


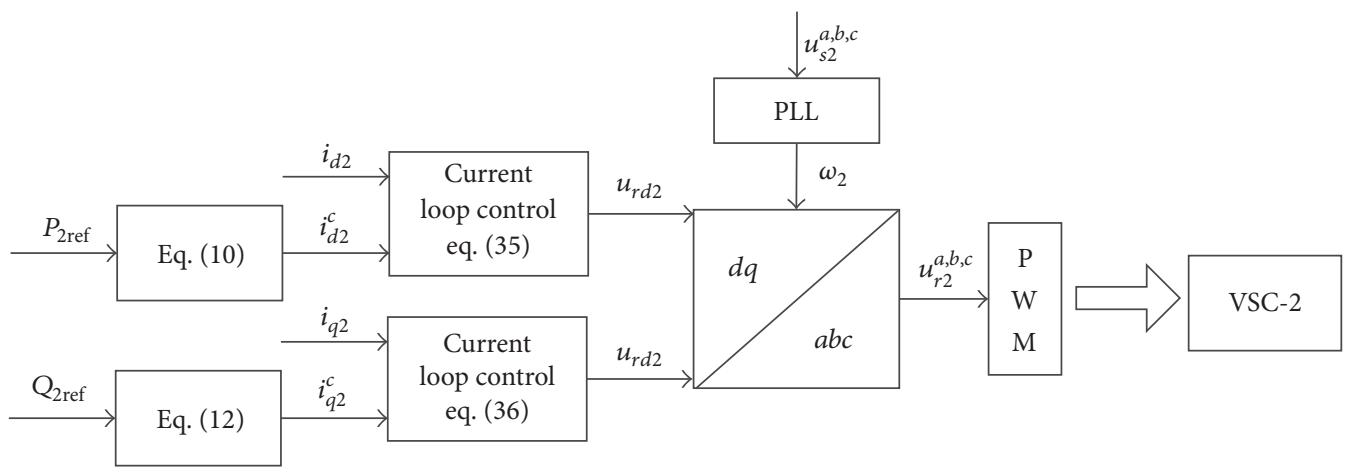

FIGURE 4: Block diagram of designed controller for VSC-2.

The tracking errors about the VSC-2 are defined as

$$
\begin{aligned}
& e_{4}=i_{d 2}-i_{d 2}^{c} \\
& e_{5}=i_{q 2}-i_{q 2}^{c},
\end{aligned}
$$

where $i_{d 2}^{c}$ and $i_{q 2}^{c}$ are the reference current in $d$-axis and $q$-axis which can be obtained from (10) and (12), respectively.

The candidate positive definite Lyapunov function $V_{3}$ is designed as

$$
V_{3}=\frac{1}{2} e_{4}^{2}+\frac{1}{2} e_{5}^{2}
$$

According to (5) and (31), the time derivative of $e_{4}$ and $e_{5}$ can be calculated as

$$
\begin{aligned}
& \dot{e}_{4}=\omega_{2} i_{q 2}-\frac{R_{2}}{L_{2}} i_{d 2}+\frac{u_{s d 2}-u_{r d 2}}{L_{2}}-\dot{i}_{d 2}^{c} \\
& e_{5}=-\omega_{2} i_{d 2}-\frac{R_{2}}{L_{2}} i_{q 2}+\frac{u_{s q 2}-u_{r q 2}}{L_{2}}-\dot{i}_{q 2}^{c} .
\end{aligned}
$$

Then, from (32)-(33), the time derivative of Lyapunov function $V_{3}$ is derived as follows:

$$
\begin{aligned}
\dot{V}_{3} & =e_{4} \dot{e}_{4}+e_{5} \dot{e}_{5} \\
= & -k_{4} e_{4}^{2}-k_{5} e_{5}^{2} \\
& +e_{4}\left(\omega_{2} i_{q 2}-\frac{R_{2}}{L_{2}} i_{d 2}+\frac{u_{s d 2}-u_{r d 2}}{L_{2}}-\dot{i}_{d 2}^{c}+k_{4} e_{4}\right) \\
& +e_{5}\left(-\omega_{2} i_{d 2}-\frac{R_{2}}{L_{2}} i_{q 2}+\frac{u_{s q 2}-u_{r q 2}}{L_{2}}-\dot{i}_{q 2}^{c}+k_{5} e_{5}\right),
\end{aligned}
$$

where $k_{4}$ and $k_{5}$ are the designed positive constant. Finally, based on (34), the two control inputs for VSC-2 are designed as

$$
\begin{aligned}
& u_{r d 2}=L_{2}\left(\omega_{2} i_{q 2}-\frac{R_{2}}{L_{2}} i_{d 2}+\frac{u_{s d 2}-u_{r d 2}}{L_{2}}-\dot{i}_{d 2}^{c}+k_{4} e_{4}\right) \\
& u_{r q 2} \\
& =L_{2}\left(-\omega_{2} i_{d 2}-\frac{R_{2}}{L_{2}} i_{q 2}+\frac{u_{s q 2}-u_{r q 2}}{L_{2}}-i_{q 2}^{c}+k_{5} e_{5}\right) .
\end{aligned}
$$

TABLE 1: The main parameters of BTB VSC-HVDC.

\begin{tabular}{lc}
\hline Parameters & Value \\
\hline Equivalent resistances $R_{1}$ and $R_{2}$ & $40 \mathrm{~m} \Omega$ \\
Equivalent inductances $L_{1}$ and $L_{2}$ & $6 \mathrm{mH}$ \\
DC-link capacitor $C$ & $4000 \mu \mathrm{F}$ \\
Nominal net DC voltage & $60 \mathrm{kV}$ \\
Each AC system nominal voltage & $138 \mathrm{kV}$ \\
Each transformer voltage ratio & $138 \mathrm{kV} / 30 \mathrm{kV}(\mathrm{Y} / \Delta)$ \\
Nominal frequencies $f_{1}$ & $50 \mathrm{~Hz}$ \\
Nominal frequencies $f_{2}$ & $60 \mathrm{~Hz}$ \\
Switching frequency $f_{s}$ & $10 \mathrm{kHz}$ \\
\hline
\end{tabular}

Thus, based on the above analysis, we can reach the goal of stability by Lyapunov stability theory because

$$
\dot{V}_{3}=-k_{4} e_{4}^{2}-k_{5} e_{5}^{2}<0 .
$$

In summary, the whole system is proved to be asymptotically stable.

The block diagram of the designed controller for VSC-2 is shown in Figure 4 to obtain a clear thought.

\section{Simulation Results}

In order to verify the effectiveness of the designed commandfiltered backstepping controller for the BTB VSC-HVDC, some simulations are carried out in this section. The structure of the system and control scheme of VSC on both sides are shown in Figures 1, 3, and 4, respectively. The main parameters of BTB VSC-HVDC are summarized in Table 1 [11]. In addition, with the purpose of making the proposed controller have better control effect, the remaining control parameters are selected as $k_{1}=260, k_{2}=100, k_{3}=60$, $k_{4}=100, k_{5}=60$. The parameters of constrained command filter are chosen as $\xi=0.707, \omega_{n}=300$, and the magnitude limit and rate limit are $500 \mathrm{~A}$ and $50000 \mathrm{~A} / \mathrm{s}$.

The whole system simulation process is $1 \mathrm{~s}$, which is divided into 5 intervals. Originally, the system runs in the standby phase from 0 to 0.05 seconds. Then, at $t=0.05 \mathrm{~s}$, $P_{2}$ is set as a step response to $10 \mathrm{MW}$ from AC system 1 to AC 


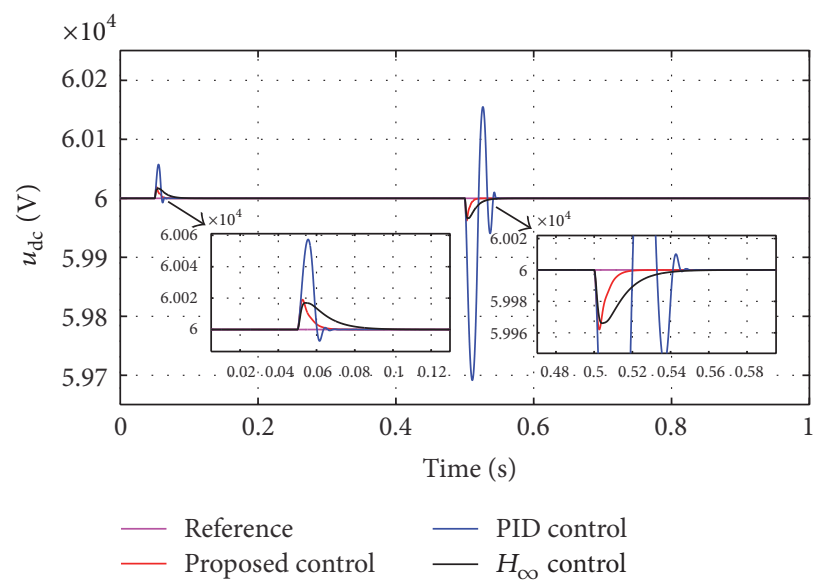

(a) DC-link voltage

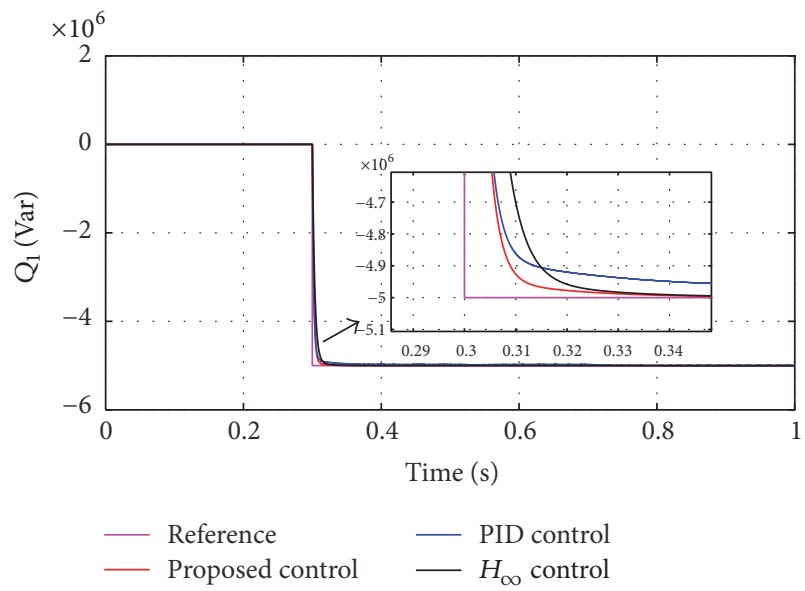

(c) Reactive power components of AC system 1

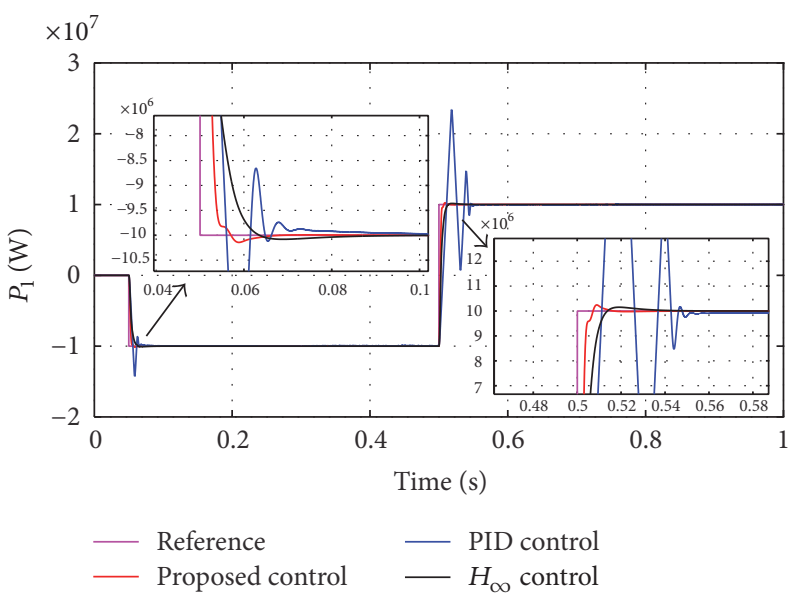

(b) Real power components of AC system 1

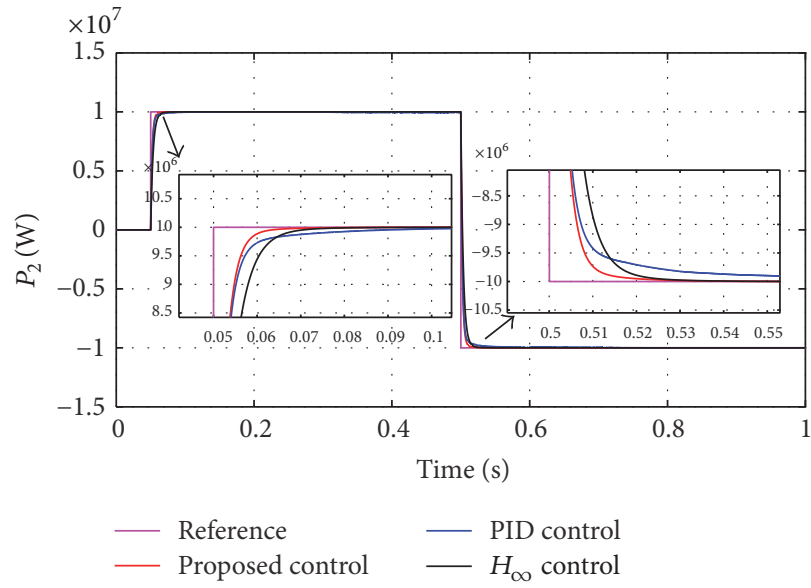

(d) Real power components of AC system 2

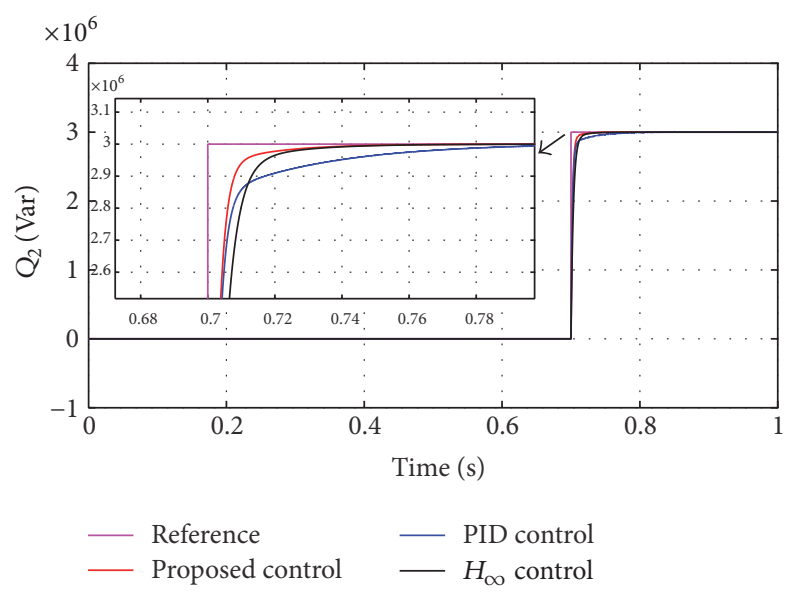

(e) Reactive power components of AC system 2

FIGURE 5: System response results of command-filtered backstepping control compared with PID control and $H_{\infty}$ controller.

system 2. At $t=0.3 \mathrm{~s}, Q_{1}$ is changed as a step response to -5 MVar. At $t=0.5 \mathrm{~s}, P_{2}$ is ramped from $10 \mathrm{MW}$ to $-10 \mathrm{MW}$, which changes as a power flow reversal from AC system 2 to AC system 1 . At $t=0.7 \mathrm{~s}, Q_{2}$ is step changed from 0 to 3 MVar for AC system 2. Meanwhile, in order to demonstrate the advantages of the designed controller, the command-filter backstepping is compared with the commonly used PID controller [12] and $H_{\infty}$ controller [27], and the simulation results are shown in Figure 5. The parameters of PID controller applied for VSC-1 and VSC-2 of BTB VSC-HVDC are listed in 


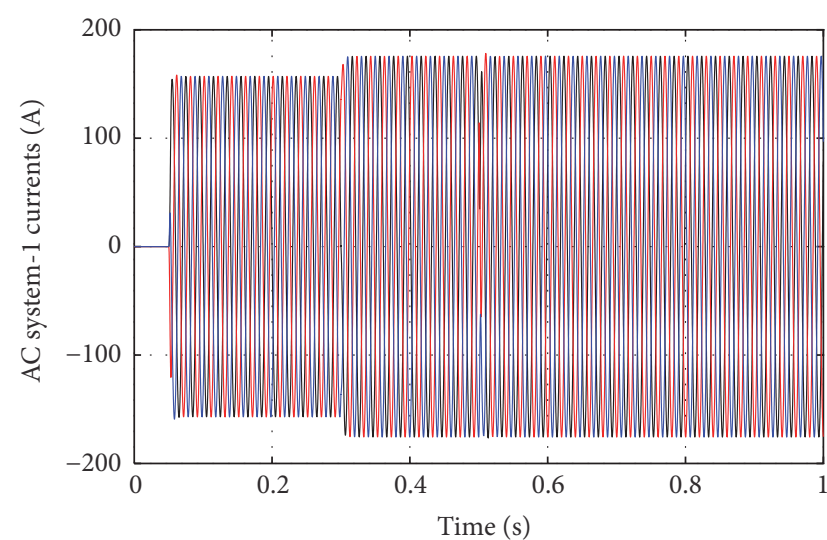

(a) Three-phase AC-side currents of AC system 1

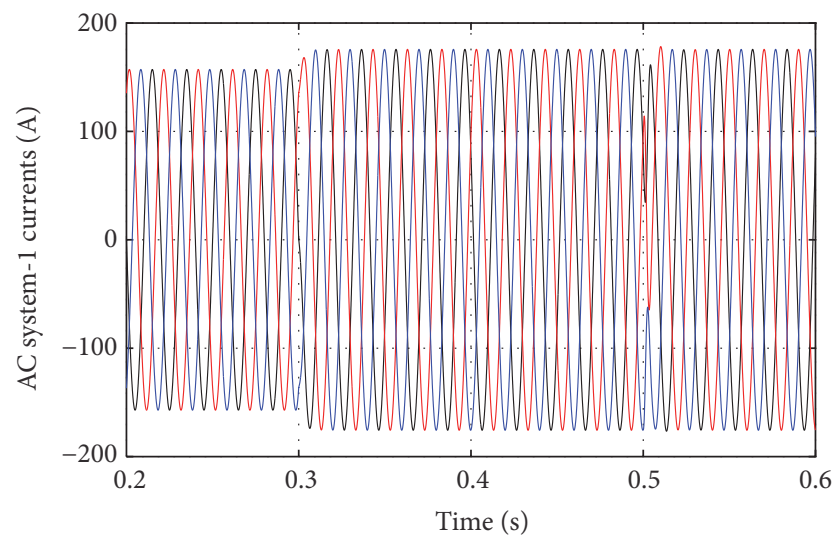

(c) Detail of three-phase AC-side currents of AC system 1

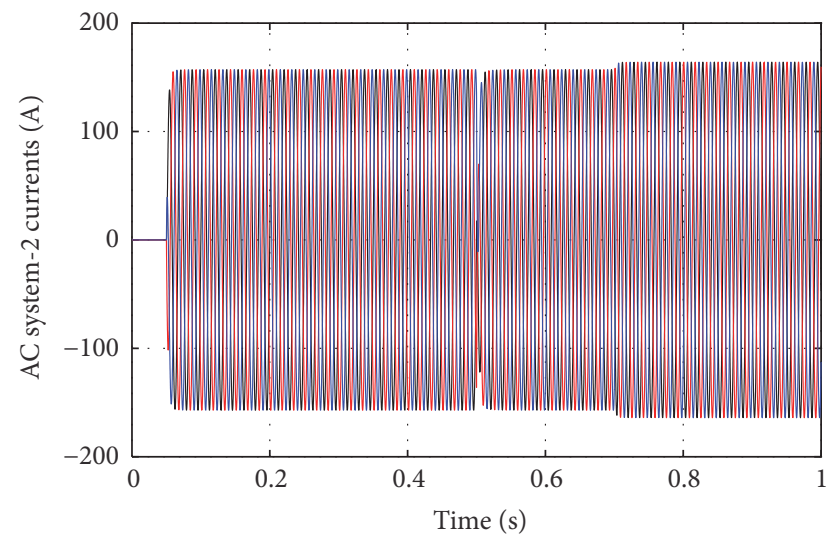

(b) Three-phase AC-side currents of AC system 2

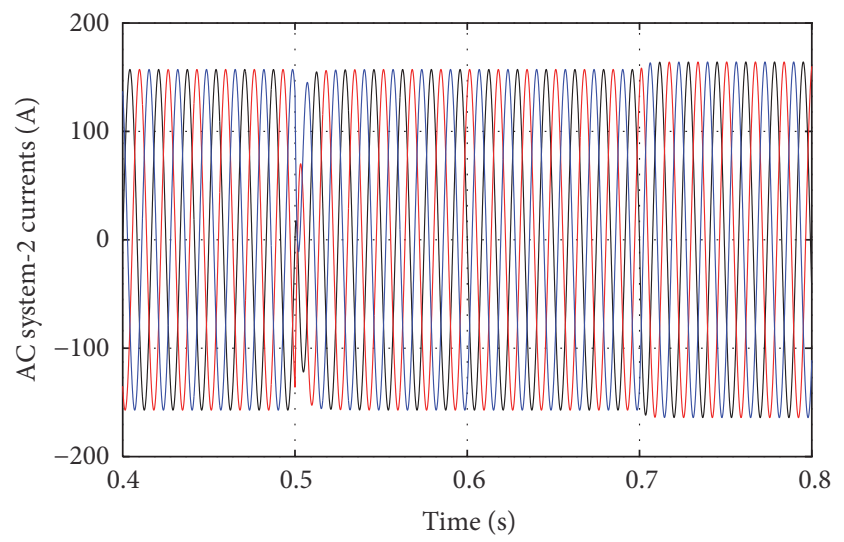

(d) Detail of three-phase AC-side currents of AC system 2

Figure 6: Three-phase AC-side currents via command-filter backstepping controller.

TABLE 2: The parameters of PID controller in BTB VSC-HVDC.

\begin{tabular}{lccc}
\hline PID controller & $k_{p}$ & $T_{i}(\mathrm{~ms})$ & $T_{d}(\mathrm{~ms})$ \\
\hline DC-link voltage & 40 & 2 & 0 \\
Real power in VSC-1 & 400 & 20 & 1 \\
Reactive power in VSC-1 & 400 & 20 & 1 \\
Real power in VSC-2 & 100 & 2 & 1 \\
Reactive power in VSC-1 & 100 & 2 & 1 \\
\hline
\end{tabular}

Table 2, and the parameter $\gamma_{1}=0.1$ of $H_{\infty}$ controller is used for VSC-1, and $\gamma_{1}=0.2$ of $H_{\infty}$ controller is used for VSC-2.

As can be seen from Figure 5(a), the DC-bus voltage is maintained closely to reference by use of the proposed control. The proposed controller and $H_{\infty}$ controller have better voltage balancing performance and robustness than conventional PID control. In addition, command-filter backstepping controller has faster response speed than $H_{\infty}$ controller; however, the $H_{\infty}$ controller has smaller overshoot when the power flow changes suddenly. Figure 5(b) shows the dynamic response of $P_{1}$ under the different step change. From Figure 5(b) we can see that proposed control has nonovershoot, smaller tracking error, and faster dynamic performance than PID control and $H_{\infty}$ controller. Figure 5(c) shows the dynamic response of reactive power components $Q_{1}$ of AC system 1. Figure 5(d) shows the dynamic response of real power components $P_{2}$ of AC system 2. Figure 5(e) shows the dynamic response of reactive power components $\mathrm{Q}_{2}$ of AC system 2. Moreover, three-phase AC-side currents of AC system 1 and AC system 2 controlled by command-filter backstepping controller are shown is Figure 6.

Figures 5 and 6 show that the control system tracks the desired signal correctly and controls the actual and reactive power requirements independently. From Figure 5, we can see that the designed controller has better dynamic performance and stronger robustness compared with the traditional PID controller and has faster response speed than $H_{\infty}$ controller. And the tuning of the parameters of proposed command-filtered backstepping controller is easier than that of the traditional PID controller. Figure 6 shows that the currents change their phases during the power flow reversal period and the operation state is well controlled according to the power reference; meanwhile, the current harmonics meet requirement of grid connection.

\section{Conclusion}

In this paper, a command-filtered backstepping controller has been designed successfully to maintain DC voltage balance 
and coordinated control of active and reactive power in BTB VSC-HVDC. First, the design process of the controller is very simple and clear, because the controller is derived from backstepping method step by step. Then, the problems of input saturation and tedious calculation of time derivative of virtual control in conventional backstepping are solved by use of command filter. Meanwhile, a filter compensation signal is considered to eliminate the adverse effects caused by command filter. Next, the stability and astringency of whole system are proved theoretically by Lyapunov method. Finally, simulation results clearly verify that the designed controller can improve the dynamic performance of the system compared to the conventional PID controller and $H_{\infty}$ controller and has stronger robustness compared with the traditional PID controller, which proves the effectiveness of proposed controller.

\section{Competing Interests}

The authors declare that they have no competing interests.

\section{Acknowledgments}

This work is supported by National Natural Science Foundation of China $(61503156,51405198)$ and the Fundamental Research Funds for the Central Universities (JUSRP11562, JUSRP51406A, and NJ20150011) and National Key Research and Development Program (2016YFD0400300) and the Science and Technology Funds for Jiangsu China (BY201501924) and Science and Technology project of Jiangsu Electric Power Company.

\section{References}

[1] Z. Bian and Z. Xu, "Fault ride-through capability enhancement strategy for VSC-HVDC systems supplying for passive industrial installations," IEEE Transactions on Power Delivery, vol. 31, no. 4, pp. 1673-1682, 2016.

[2] B. Li, F. Jing, J. Jia et al., "Research on saturated iron-core superconductive fault current limiters applied in VSC-HVDC systems," IEEE Transactions on Applied Superconductivity, vol. 26, no. 7, pp. 1-5, 2016.

[3] Y. S. Borovikov, A. S. Gusev, A. O. Sulaymanov et al., "A hybrid simulation model for VSC HVDC," IEEE Transactions on Smart Grid, vol. 7, no. 5, pp. 2242-2249, 2016.

[4] L. Chen, H. Chen, Z. Shu, G. Zhang, T. Xia, and L. Ren, "Comparison of inductive and resistive SFCL to robustness improvement of a VSC-HVDC system with wind plants against DC fault," IEEE Transactions on Applied Superconductivity, vol. 26, no. 7, pp. 1-8, 2016.

[5] M. I. Daoud, A. M. Massoud, A. S. Abdel-Khalik, A. Elserougi, and S. Ahmed, "A flywheel energy storage system for fault ride through support of grid-connected VSC HVDC-based offshore wind farms," IEEE Transactions on Power Systems, vol. 31, no. 3, pp. 1671-1680, 2016.

[6] M. Chaves, E. Margato, J. F. Silva, S. F. Pinto, and J. Santana, "HVDC transmission systems: bipolar back-to-back diode clamped multilevel converter with fast optimum-predictive control and capacitor balancing strategy," Electric Power Systems Research, vol. 81, no. 7, pp. 1436-1445, 2011.
[7] M. Saeedifard, R. Iravani, and J. Pou, "A space vector modulation strategy for a back-to-back five-level HVDC converter system," IEEE Transactions on Industrial Electronics, vol. 56, no. 2, pp. 452-466, 2009.

[8] M. Saeedifard and R. Iravani, "Dynamic performance of a modular multilevel back-to-back HVDC system," IEEE Transactions on Power Delivery, vol. 25, no. 4, pp. 2903-2912, 2010.

[9] J. Qin and M. Saeedifard, "Predictive control of a modular multilevel converter for a back-to-back HVDC system," IEEE Transactions on Power Delivery, vol. 27, no. 3, pp. 1538-1547, 2012.

[10] L. Zhang, L. Harnefors, and H.-P. Nee, "Interconnection of two very weak AC systems by VSC-HVDC links using powersynchronization control," IEEE Transactions on Power Systems, vol. 26, no. 1, pp. 344-355, 2011.

[11] S. Bouafia, A. Benaissa, M. Bouzidi, and S. Barkat, "Backstepping control of three-levels VSC based back-to-back HVDC system," in Proceedings of the 3rd International Conference on Systems and Control (ICSC '13), pp. 900-905, Algiers, Algeria, October 2013.

[12] H. Nikkhajoei and R. Iravani, "Dynamic model and control of AC-DC-AC voltage-sourced converter system for distributed resources," IEEE Transactions on Power Delivery, vol. 22, no. 2, pp. 1169-1178, 2007.

[13] I. Kanellakopoulos, P. V. Kokotovic, and A. S. Morse, "Systematic design of adaptive controllers for feedback linearizable systems," IEEE Transactions on Automatic Control, vol. 36, no. 11, pp. 1241-1253, 1991.

[14] W. Yan, J. Huang, and D. Xu, "Adaptive command-filtered backstepping control for linear induction motor via projection algorithm," Mathematical Problems in Engineering, vol. 2016, Article ID 4720126, 13 pages, 2016.

[15] G.-D. Wang, R.-J. Wai, and Y. Liao, "Design of backstepping power control for grid-side converter of voltage source converter-based high-voltage $\mathrm{dc}$ wind power generation system," IET Renewable Power Generation, vol. 7, no. 2, pp. 118-133, 2013.

[16] Q. Sun, J. Zhou, J. M. Guerrero, and H. Zhang, "Hybrid threephase/single-phase microgrid architecture with power management capabilities," IEEE Transactions on Power Electronics, vol. 30, no. 10, pp. 5964-5977, 2015.

[17] A. Ajami, A. M. Shotorbani, and M. P. Aagababa, "Application of the direct Lyapunov method for robust finite-time power flow control with a unified power flow controller," IET Generation, Transmission and Distribution, vol. 6, no. 9, pp. 822-830, 2012.

[18] S.-Y. Ruan, G.-J. Li, X.-H. Jiao, Y.-Z. Sun, and T. T. Lie, "Adaptive control design for VSC-HVDC systems based on backstepping method," Electric Power Systems Research, vol. 77, no. 5-6, pp. 559-565, 2007.

[19] M. Ayari, M. A. Ghariani, M. M. Belhaouane, and N. Benhadj Braiek, "Integral backstepping control design for VSC-HVDC systems," in Proceedings of the 15th International Conference on Sciences and Techniques of Automatic Control and Computer Engineering (STA '14), pp. 698-703, December 2014.

[20] J. Wu, Z.-X. Wang, G.-Q. Wang, X.-F. Lu, and J.-L. Zou, "Backstepping control for voltage source converter-high voltage direct current grid side converter," Control Theory \& Applications, vol. 30, no. 11, pp. 1408-1413, 2013.

[21] Y. Liao and G. Wang, "A new control strategy for DFIG wind farm with VSC-HVDC integration," WSEAS Transactions on Circuits and Systems, vol. 12, no. 7, pp. 221-231, 2013. 
[22] B. Parkhideh and S. Bhattacharya, "Vector-controlled voltagesource-converter-based transmission under grid disturbances," IEEE Transactions on Power Electronics, vol. 28, no. 2, pp. 661672, 2013.

[23] Y. Qiu, X. Liang, Z. Dai, J. Cao, and Y. Chen, “Backstepping dynamic surface control for a class of non-linear systems with time-varying output constraints," IET Control Theory and Applications, vol. 9, no. 15, pp. 2312-2319, 2015.

[24] S.-C. Tong, Y.-M. Li, G. Feng, and T.-S. Li, “Observer-based adaptive fuzzy backstepping dynamic surface control for a class of MIMO nonlinear systems," IEEE Transactions on Systems, Man, and Cybernetics, Part B: Cybernetics, vol. 41, no. 4, pp. 1124-1135, 2011.

[25] Y. Wang, L. Cao, S. Zhang, X. Hu, and F. Yu, “Command filtered adaptive fuzzy backstepping control method of uncertain nonlinear systems," IET Control Theory and Applications, vol. 10, no. 10, pp. 1134-1141, 2016.

[26] G. Cui, S. Xu, F. L. Lewis, B. Zhang, and Q. Ma, "Distributed consensus tracking for non-linear multi-agent systems with input saturation: a command filtered backstepping approach," IET Control Theory and Applications, vol. 10, no. 5, pp. 509-516, 2016.

[27] H. Liang, G. Li, G. Li, P. Li, and M. Yin, "Analysis and design of $H_{\infty}$ controller in VSC HVDC systems," in Proceedings of the IEEE/PES Transmission and Distribution Conference and Exhibition: Asia and Pacific, pp. 1-6, August 2005. 


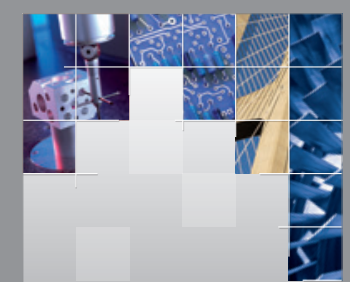

\section{Enfincering}
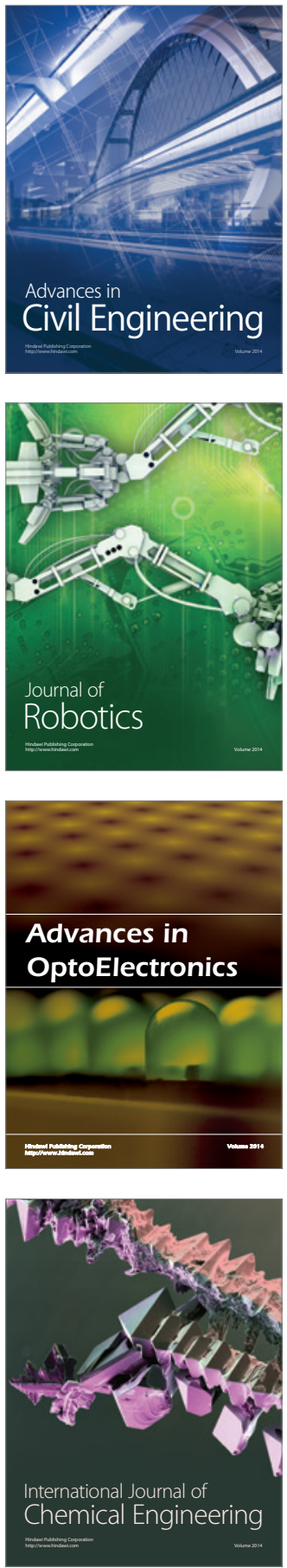

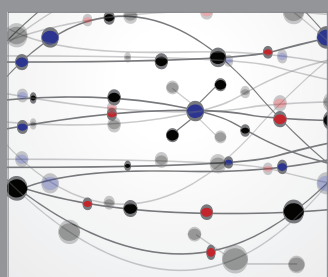

The Scientific World Journal

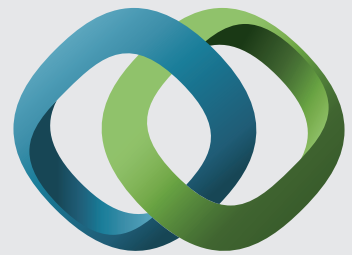

\section{Hindawi}

Submit your manuscripts at

https://www.hindawi.com
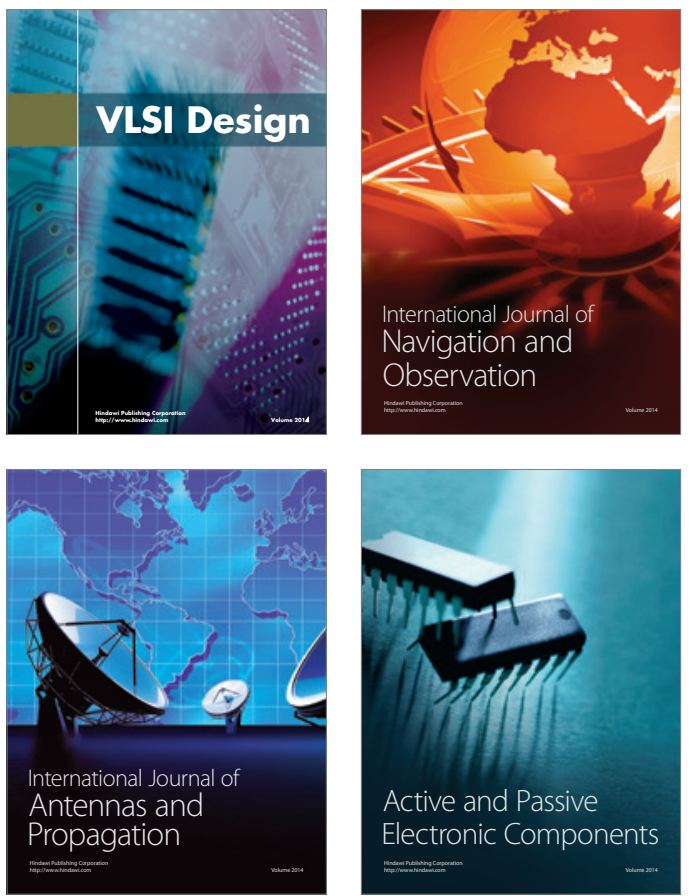
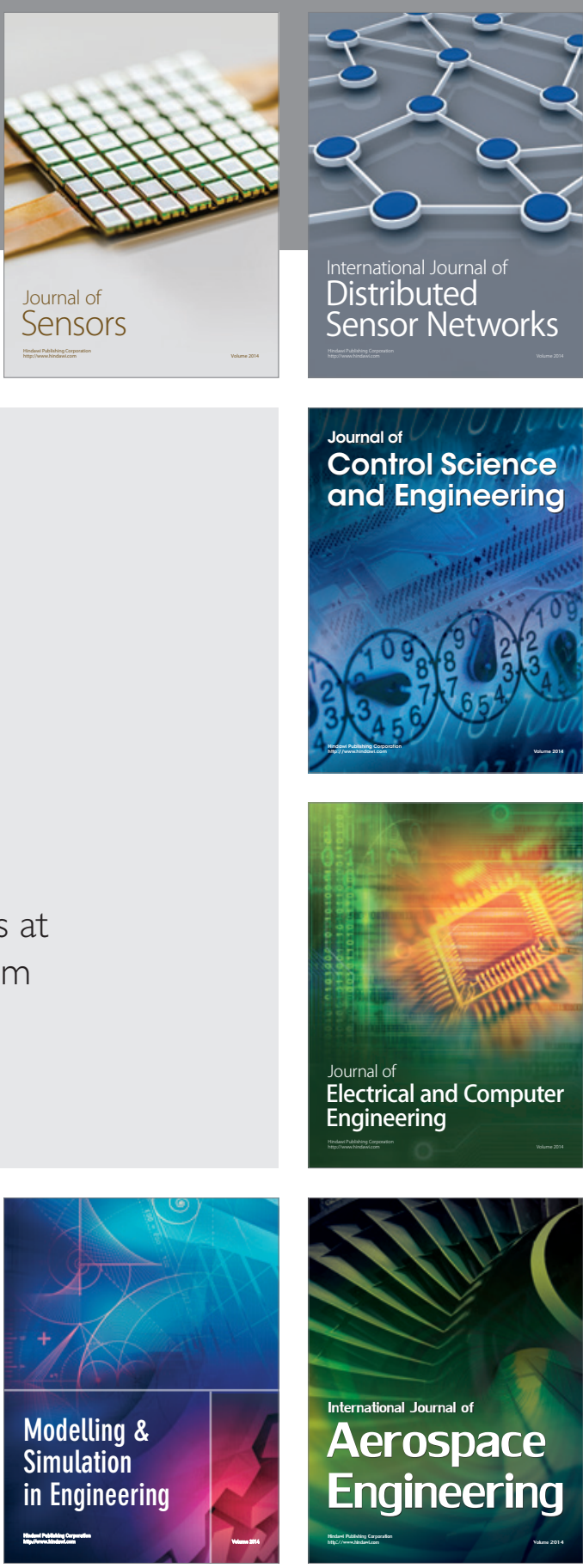

International Journal of

Distributed

Sensor Networks

$-$

Joumal of

Control Science

and Engineering
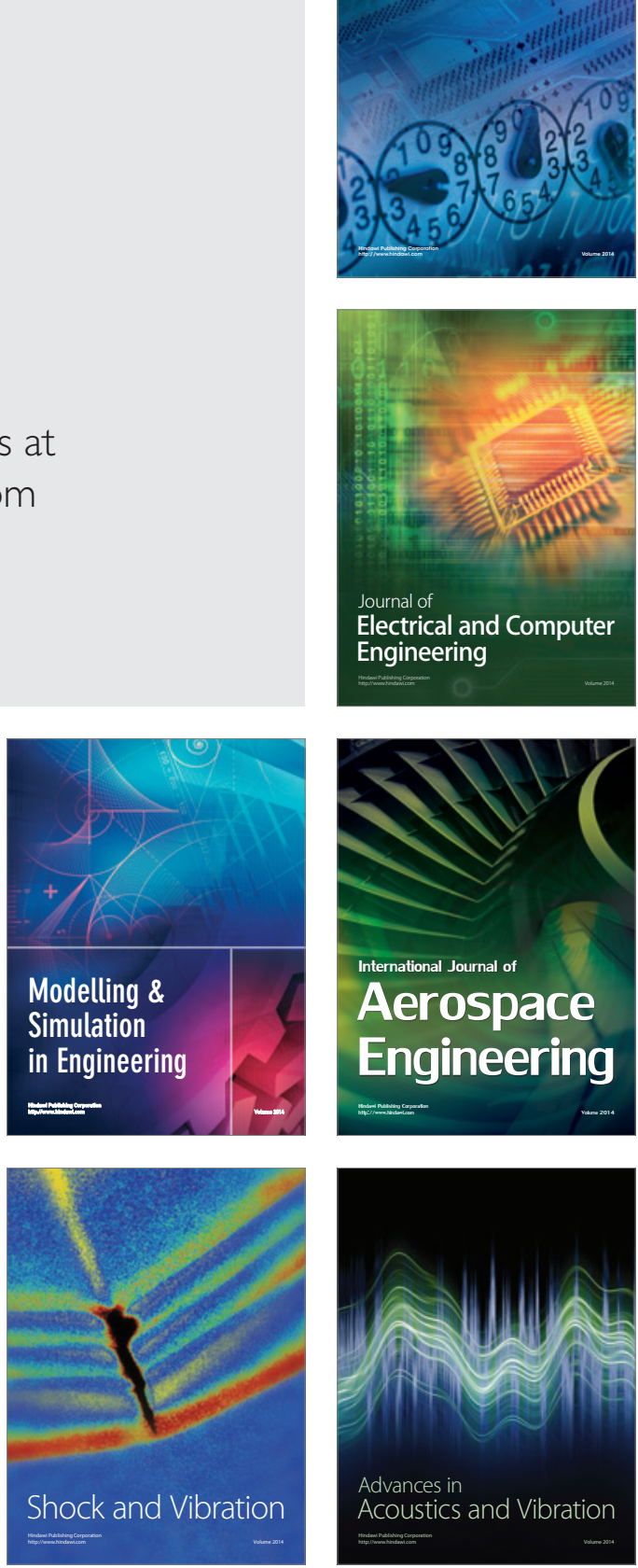